\title{
Genetic Transfer in Mycobacterium phlei
}

\author{
By S. M. GELBART AND S. E. JUHASZ \\ Department of Microbiology, Loyola University of Chicago, \\ Stritch School of Medicine, Maywood, Illinois 60153, and \\ Research Service, Veterans Administration Hospital, \\ Hines, Illinois 6014I, U.S.A.
}

\section{(Accepted for publication 4 November 1970)}

Transfer of genetic information in the genus Mycobacterium has been reported (Juhasz, I960; Redmond, Ward \& Wright, 1967) but the role of phage in such transfers could not be established. We would like to report on genetic transfer in $M$. phlei in which transducing phage Bo2 plays a major role.

The donor strain, Mycobacterium phlei SN I09, obtained from the Borstel Culture Collection, Borstel, West Germany, could grow on D-xylose $\left(x y l^{+}\right)$when this sugar was present as the sole carbon source, and was sensitive to $\mathrm{I} \cdot 0 \mu \mathrm{g} . / \mathrm{ml}$. streptomycin (str-s). The recipient strain, a mutant of $M$. phlei $\mathrm{F} 89$ resistant to $100 \mu \mathrm{g} . / \mathrm{ml}$. streptomycin (str-r), could not utilize D-xylose $\left(x y l^{-}\right)$as a carbon source. Original $M$. phlei F 89 was obtained from S. Froman, Olive View Hospital, Olive View, California. The phage employed was mycobacteriophage phlei Bo 2, originally designated $\mathrm{B} 2$, isolated from dung and propagated on $M$. phlei F89 (Juhasz \& Bönicke, 1965). The selective medium chosen for these experiments was a minimal medium (Gordon \& Mihm, I959) containing I \% D-xylose (Pfanstiehl), to which $50 \mu \mathrm{g} . / \mathrm{ml} . \mathrm{FeCl}_{3}$ and $50 \mu \mathrm{g} . / \mathrm{ml}$. streptomycin sulphate (Sigma) were added. Several controls were employed. These consisted of bacteria treated with (I) heat-killed phage (autoclaved at $15 \mathrm{lb}$. pressure for I 5 min.); (ii) phage and DNase (Calbiochem); (iii) heat-killed (autoclaved) phage and DNase; and (iv) sterile heart infusion broth (Difco) in place of phage.

In our experiments phage Bo 2 was propagated on the donor strain Mycobacterium phlei SN I09 $\left(x y l^{+}\right.$, str-s), harvested, filtered and tested for bacterial sterility. Sterile phage preparations were then used to infect the recipient $M$. phlei F89 (xyl-, str-r). Various multiplicities of infection were tried. Positive results were obtained with multiplicities of infection of $\mathrm{I} \cdot 0$ and $2 \cdot 0$, the results being proportional to the phage concentrations employed. However, if the phage concentration was too high, background bacterial growth, stemming from nutrients present in the phage preparation itself, made isolation of $x y l^{+}$transductants difficult. The phage-bacterium mixture was incubated at $37^{\circ}$ for $48 \mathrm{~h}$. and subsequently inoculated on to the selective medium. Growth was recorded after 4 weeks. In order to insure that mutants could in fact utilize xylose and that bacterial growth had not been due to nutrients in the phage inoculum, randomly selected colonies from each experiment were washed twice in physiological saline and reinoculated on to the selective medium. All the colonies thus tested were able to grow on xylose as sole carbon source. Phage conversion did not seem to account for the emergence of the $x y l^{+}$character since infection with phage Bo 2, which has been propagated previously on $\mathrm{F} 89\left(x y l^{-}\right.$, str-r) did not convert F $89\left(x y l^{-}\right.$, str-r) to $x y l^{+}$. 
Transfer of the $x y l^{+}$marker by transduction is firmly supported by the data from four transfer experiments summarized in Table $\mathbf{I}$. The larger number of prototrophic colonies obtained with live as opposed to heat-killed phage, the proportionality of the number of such colonies to the number of phage employed, and, finally, the transfer activity retained by DNase-treated phage are major characteristics of the known transduction systems. The peculiarity of the transfer system presented in this paper was,

Table I. Transfer of the $x^{\prime} l^{+}$character to Mycobacterium phlei F89 (xyl-, str-r)

\begin{tabular}{lllll}
\multicolumn{1}{c}{ Experiment* } & A & B & C & D \\
Phage input/ml. (plaque-forming units) & $\mathrm{I} \cdot 2 \times 10^{8}$ & $3 \times 10^{8}$ & $8 \times 10^{8}$ & $4 \times 10^{8}$ \\
Multiplicity of infection & $\mathrm{I} \cdot 2$ & $\mathrm{I} \cdot 0$ & $2 \cdot 0$ & $\mathrm{I} \cdot 0$ \\
I. Bacteria and phage mixture & $2 \mathrm{I} 7$ & 481 & $103 \mathrm{I}$ & $45 \mathrm{I}$ \\
2. Bacteria and phage and DNase mixture & - & $41 \mathrm{I}$ & - & 367 \\
3. Bacteria and heat-killed phage mixture & - & 84 & 343 & $\mathrm{I08}$ \\
4. Bacteria and heat-killed phage and & - & - & 56 & - \\
$\quad$ DNase mixture & & & 38 & -
\end{tabular}

* Numbers in columns refer to the number of colonies obtained on 20 plates containing $0 \cdot 1 \mathrm{ml}$. amounts of the incubation mixture/plate (in the presence of xylose as sole carbon source).

however, that heat-killed phage preparations retained part of the original transfer activity. Upon treatment with DNase, this residual activity of heat-killed phage disappeared and the number of spontaneous revertants was comparable with that found when heart infusion broth replaced phage. Since the heat-killed phage appeared to retain the transfer activity lost when the phage preparation was treated with DNase (sum of lines two and three of Table I compared with line one) one can hardly escape the conclusion that the observed residual activity was due to transformation by bacterial DNA. Direct evidence for transformation to $x y l^{+}$of Mycobacterium phlei $\mathrm{F} 89$ will be obtained only upon isolation of biologically active DNA from either donor SN 109 or from phage Bo 2 which has been propagated previously on SN IO9.

\section{ADDENDUM}

After this paper was submitted for publication an article appeared in Nature, London, on 'Transduction in Mycobacterium smegmatis'. (C. V. Sundar Raj \& T. Ramakrishnan, 1970, Nature London 228, 280.)

\section{REFERENCES}

Gordon, R. E. \& MirM, J. A. (1959). Comparison of some species of Mycobacterium. Journal of General Microbiology 2r, 736-748.

JUHASZ, S. E. (1960). Interspecific hybridization among mycobacteria. Nature, London 185, 265.

JuHASZ, S. E. \& BöNICKE, R. (1965). Possible classification of rapidly growing mycobacteria on the basis of their phage susceptibility. Canadian Journal of Microbiology II, 235-24I.

REDMOND, W. B., WARD, D. M. \& WRIGHT, B. (1967). Genetic transfer of drug resistance in mycobacteria. Bacteriological Proceedings, p. 55. 